\title{
Effects of Pantothenic Acid Supplementation on Adrenal Steroid Secretion from Male Rats
}

\author{
Sukanya Jaroenporn, ${ }^{a, b}$ Tatsuya Yamamoto, ${ }^{a, b}$ Asuka Itabashi, ${ }^{b}$ Katsuhiro NaKamura, ${ }^{c}$ \\ Isao Azumano, ${ }^{c}$ Gen Watanabe, ${ }^{a, b}$ and Kazuyoshi TAYA ${ }^{*, a, b}$ \\ ${ }^{a}$ Department of Basic Veterinary Science, The United School of Veterinary Sciences, Gifu University; Gifu 501-1193, \\ Japan: ${ }^{b}$ Laboratory of Veterinary Physiology, Department of Veterinary Medicine, Faculty of Agriculture, Tokyo University \\ of Agriculture and Technology; Tokyo 183-8509, Japan: and ${ }^{c}$ Daiichi Fine Chemical Co.; Tokyo 103-0025, Japan. \\ Received September 19, 2007; accepted February 8, 2008; published online March 10, 2008
}

The effects of pantothenic acid-supplementation on the adrenal secretion of corticosterone and progesterone in male rats were investigated using an in vitro cell culture system. Male rats at $21 \mathrm{~d}$ of age were given $0.03 \%$ pantothenic acid in their drinking water for 9 weeks. After 9 weeks of treatment, the animals were decapitated, and adrenal cells were cultured in the absence or presence of rat adrenocorticotropic hormone (ACTH; $10^{-15}$ to $10^{-10} \mathrm{M}$ ) and/or ovine prolactin (oPRL; $10^{-9}$ to $10^{-7} \mathrm{M}$ ) for $4 \mathrm{~h}$. Adrenal cells in pantothenic acid-treated rats exhibited higher basal levels of corticosterone and progesterone than control rats. The response of ACTH and/or PRL on corticosterone and progesterone release was higher in the pantothenic acid-treated rats than in the control rats. In addition, PRL increased the stimulatory effect of ACTH-induced corticosterone secretion in both normal and pantothenic acid-treated rats. These results clearly demonstrated that pantothenic acid supplementation stimulates the ability of adrenal cells in male rats to secrete corticosterone and progesterone. Additionally, these results also showed that pantothenic acid supplementation induced adrenal hyperresponsiveness to ACTH stimulation, and PRL further stimulated adrenal sensitivity to ACTH.

Key words adrenal gland; corticosterone; pantothenic acid; rat

Pantothenic acid, a member of the B-vitamin family, is an essential nutrient to all forms of life. ${ }^{1)}$ Pantothenic acid is involved in a number of biological reactions, including the production of energy, the catabolism of fatty acids and amino acids, the synthesis of fatty acids, phospholipids, sphingolipids, cholesterol and steroid hormones, and the synthesis of heme and the neurotransmitter acetylcholine. Pantothenic acid is a component of coenzyme A (CoA), an essential coenzyme in a variety of reactions that sustain life. CoA is required for chemical reactions that generate enzyme from food (fat, carbohydrates, and proteins). Additionally, the synthesis of essential fats, cholesterol, and steroid hormones requires $\mathrm{CoA} .{ }^{2)}$ Indeed, the primary target of $\mathrm{CoA}$ is acetate, ${ }^{3)}$ the precursor of cholesterol synthesis. ${ }^{4}$

Pantothenic acid is known to be essential for the maintenance of normal adrenal structure. ${ }^{5,6)}$ It has been reported that adrenocortical function is impaired in pantothenic aciddeficient rats. ${ }^{6-8)}$ Hurley and Morgan ${ }^{7)}$ have suggested that pantothenic acid deficiency produces adrenal hypofunction. The function of pantothenic acid in the adrenal cortex, however, has not been thoroughly elucidated, though the involvement of pantothenic acid in steroidogenesis in the adrenal cortex has been suggested for a long time. In the present study, we isolated adrenal cells from normal and pantothenic acid-treated rats and further investigated the putative different effects of prolactin (PRL) and/or adrenocorticotropic hormone (ACTH) on the secretion of corticosterone in vitro. The concentrations of progesterone in plasma and culture media were also measured as the precursor of corticosterone.

\section{MATERIALS AND METHODS}

Materials Dulbecco's modified Eagle's medium (DMEM), MEM non-essential amino acids solution, penicillin and streptomycin (Invitrogen, Burlington, ON, Canada), HEPES
(Dojindo, Gaitherburg, Maryland, U.S.A.), collagenase type $\mathrm{V}$, deoxyribonuclease, fetal bovine serum (Sigma-Aldrich Corp., St. Louis, MO, U.S.A.), rat ACTH (AFPRFR7890), ovine PRL (AFP10692C) (NIDDK, NIH, Torrance, CA, U.S.A.), and pantothenic acid (Daiichi Fine Chemical Co., Tokyo, Japan) were purchased from the sources indicated.

Animals Male Wistar Imamichi rats, $21 \mathrm{~d}$ of age, from Imamichi Institute for Animal Reproduction (Kasumigaura, Ibaraki, Japan), were used. The rats were kept in the Laboratory of Veterinary Physiology at the Tokyo University of Agriculture and Technology under standard housing conditions; controlled lighting (lights on $05.00 \mathrm{~h}-19.00 \mathrm{~h}$ ), temperature $\left(23 \pm 2{ }^{\circ} \mathrm{C}\right)$ and humidity $(50 \pm 10 \%)$. A rat diet (MR-Breeder, Nosan Corporation, Yokohama, Japan) and water were given to the animals ad libitum. The experimental protocol was approved by the Animal Ethical Committee in accordance with the Guide for the Care and Use of Laboratory Animals prepared by Tokyo University of Agriculture and Technology.

Experimental Designs and Incubation of Adrenal Cells Male rats were treated with 0 (control) or $0.03 \%$ pantothenic acid from $21 \mathrm{~d}$ of age in their drinking water for 9 weeks. After 9 weeks of pantothenic acid treatment, 21 animals in each group were killed by decapitation, and the adrenal glands were immediately removed. The whole glands were used, and the procedures were performed according to previously described methods. ${ }^{9)}$ To measure the effects of pantothenic acid on ACTH-, or PRL-stimulated release of corticosterone and progesterone, adrenal cells were pre-incubated for $24 \mathrm{~h}$ at $37^{\circ} \mathrm{C}$ in a humidified atmosphere $(95 \%$ air $/ 5 \%$ $\mathrm{CO}_{2}$ ) with DMEM medium supplemented with $2 \%$ fetal bovine serum, $100 \mathrm{U} / \mathrm{ml}$ penicillin, and $100 \mu \mathrm{g} / \mathrm{ml}$ streptomycin. After $24 \mathrm{~h}$ in culture, the incubation medium was replaced by the same medium as previously used, and the cells were then incubated in the absence or presence of rat ACTH 
$\left(10^{-15}\right.$ to $\left.10^{-10} \mathrm{M}\right)$ and/or oPRL $\left(10^{-9}\right.$ to $\left.10^{-6} \mathrm{M}\right)$ for $4 \mathrm{~h}$. At the end of the 4-h incubation period, the supernatant was decanted and stored at $-20^{\circ} \mathrm{C}$ until assayed for hormone concentration (corticosterone and progesteone).

Radioimmunoassay (RIA) The concentrations of corticosterone $^{10)}$ and progesterone ${ }^{11)}$ were measured by double antibody RIAs using ${ }^{125} \mathrm{I}$-labeled radioligands after a single ether extraction as described previously. The assay procedure was as follows: ${ }^{125} \mathrm{I}$-corticosterone or ${ }^{125} \mathrm{I}$-progesterone (GE Healthcare, Buckinghamshire, U.K.) was diluted with $0.05 \mathrm{M}$ phosphate buffer saline (PBS) containing 1\% bovine serum albumin (BSA). Antiserum to corticosterone (TUAT-VPC1) or progesterone (GDN337) was diluted with $0.05 \mathrm{M}$ PBS containing $0.05 \mathrm{M}$ ethylenediamine tetraacetic acid, $2 \mathrm{Na}$ salt, dehydrate (EDTA) and 0.4\% normal goat serum (NGS). Donkey anti-sheep gamma globulin serum (ASGG) was diluted with $0.05 \mathrm{M}$ PBS containing 5\% polyethylene glycol 6000 (PEG) to $1: 50$ dilution. Plasma or supernatant $(0.1-1 \mu \mathrm{l}$ for corticosterone and 5-10 $\mu \mathrm{l}$ for progesterone) and standard were diluted to $400 \mu \mathrm{l}$ with distilled water and extracted once with $2 \mathrm{ml}$ of diethyl ether. The tubes were then placed in a dry ice-ethanol bath to freeze the aqueous phase. The ether phase was then decanted into a new tube and dried at $50^{\circ} \mathrm{C}$. One hundred microliters of $1 \%$ BSA, antiserum and labeled ligand $(50-100 \mathrm{~Bq} / 100 \mu)$ were added to each tube and the extract was dissolved by agitation and incubated at $4{ }^{\circ} \mathrm{C}$ for $24 \mathrm{~h}$. Then, $100 \mu \mathrm{l}$ of ASGG was added to each tube. After further incubation for $24 \mathrm{~h}$, the antibody bound hormone was separated from the free hormone by centrifugation at $4{ }^{\circ} \mathrm{C}$ $1700 \mathrm{~g}$ for $30 \mathrm{~min}$. The supernatant was carefully decanted and the precipitate was counted in an automatic gamma counter $\left(\right.$ COBAR $^{\mathrm{TM}}$ Quantum; Packard Company, Downers Grove, IL, U.S.A.). The concentrations of corticosterone and progesterone were calculated using a standard curve. The intra- and interassay coefficients of variation were 9.8 and $12.9 \%$ for corticosterone and 9.5 and $11.2 \%$ for progesterone, respectively. The lower limits of the assay sensitivity were $5 \mathrm{pg} /$ tube for corticosterone and $0.6 \mathrm{pg} /$ tube for progesterone.

Statistical Analysis The results are expressed as the mean \pm standard error of the mean (S.E.M.). Statistical analyses were performed using the Statistical Package for the Social Sciences (SPSS) program. The paired-sample $t$-test was used for comparison of organ weights between the control and treatment groups. Differences among times of sampling were evaluated by one-way analyses of variance (ANOVA) for factorial or repeated measure design with posthoc testing by the least significant difference (LSD) test. $p$ values of less than 0.05 were considered to be statistically significant.

\section{RESULTS}

Body Weights and Adrenal Gland Weights Body weights and adrenal gland weights are shown in Table 1. The body weights were not significantly different between the control and pantothenic acid-treated groups. Although a slight increase in adrenal gland weight in the pantothenic acid group was observed, no statistically significant differences were detected between the control and pantothenic acid groups.
Table 1. Body Weights and Weights of Adrenal Glands of Male Rats Treated with Pantothenic Acid

\begin{tabular}{lcc}
\hline \hline Treatment & Body weight $(\mathrm{g})$ & Adrenal weight $(\mathrm{mg})$ \\
\hline Control & $413.4 \pm 8.0$ & $47.90 \pm 2.6$ \\
Pantothenic acid & $407.0 \pm 4.5$ & $56.27 \pm 3.9$
\end{tabular}

Each value is expressed as the mean \pm S.E.M. of six animals.

Table 2. Plasma Concentration of Corticosterone and Progesterone in Adult Male Rats Treated with Pantothenic Acid

\begin{tabular}{lcc}
\hline \hline Treatment & Corticosterone $(\mathrm{ng} / \mathrm{ml})$ & Progesterone $(\mathrm{ng} / \mathrm{ml})$ \\
\hline Control & $90.9 \pm 31.2$ & $1.5 \pm 0.6$ \\
Pantothenic acid & $198.8 \pm 38.8^{*}$ & $1.8 \pm 0.4$
\end{tabular}

Each value is expressed as the mean \pm S.E.M. of six animals. $* p<0.05$, as compared with control.

Table 3. The Basal Release of Corticosterone and Progesterone by Cultured Rat Adrenal Cell of Male Rats Treated with Pantothenic Acid during $4 \mathrm{~h}$ Incubation

\begin{tabular}{lcc}
\hline \hline Treatment & $\begin{array}{c}\text { Corticosterone } \\
\left(\mathrm{ng} / 5 \times 10^{4} \text { cells } / 4 \mathrm{~h}\right)\end{array}$ & $\begin{array}{c}\text { Progesterone } \\
\left(\mathrm{ng} / 5 \times 10^{4} \text { cells } / 4 \mathrm{~h}\right)\end{array}$ \\
\hline Control & $1.17 \pm 0.14$ & $0.36 \pm 0.06$ \\
Pantothenic acid & $2.28 \pm 0.27^{* *}$ & $0.67 \pm 0.04 * *$
\end{tabular}

Each value is expressed as the mean \pm S.E.M. of three different experiments performed in quadruplicate. $* * p<0.01$ as compared with control

Plasma Corticosterone and Progesterone Basal plasma levels of corticosterone significantly increased in pantothenic acid-treated rats as compared with control rats (Table 2). The basal levels of progesterone in the pantothenic acid rats were also high compared with those of control rats, although there were no significant differences between two groups.

Basal and ACTH-Stimulated Corticosterone and Progesterone Release in Vitro The basal releases of corticosterone and progesterone by adrenal cells were significantly greater in the pantothenic acid-treated rats than in the controls (Table 3). Administration of ACTH $\left(10^{-15}\right.$ to $\left.10^{-10} \mathrm{M}\right)$ resulted in a dose-dependent increase in corticosterone release in both control and pantothenic acid rats (Fig. 1A). On the other hand, a clear dose-dependent increase in progesterone was observed in cultured adrenal cells from the pantothenic acid rats but not the control rats (Fig. 1B). Dispersed adrenal cells from the pantothenic acid rats required smaller amounts of ACTH to stimulate corticosterone $\left(10^{-13} \mathrm{M}\right)$ and progesterone $\left(10^{-14} \mathrm{M}\right)$ levels significantly above basal levels in comparison with those required by control rats $\left(10^{-12} \mathrm{M}\right.$, $10^{-13} \mathrm{M}$, respectively). Moreover, the corticosterone and progesterone releases in response to ACTH $\left(10^{-15}\right.$ to $\left.10^{-10} \mathrm{M}\right)$ were markedly increased in adrenal cells from pantothenic acid rats compared with those from control rats.

oPRL-Stimulated Corticosterone and Progesterone Release in Vitro Administration of oPRL $\left(10^{-7} \mathrm{M}\right)$ resulted in a significant increase in corticosterone release in both control and pantothenic acid rats (Fig. 2A). However, the increase in progesterone release by oPRL treatment was observed only in pantothenic acid rats (Fig. 2B). The corticosterone release in response to oPRL $\left(10^{-7} \mathrm{M}\right)$ was markedly increased in adrenal cells from pantothenic acid rats compared with those 


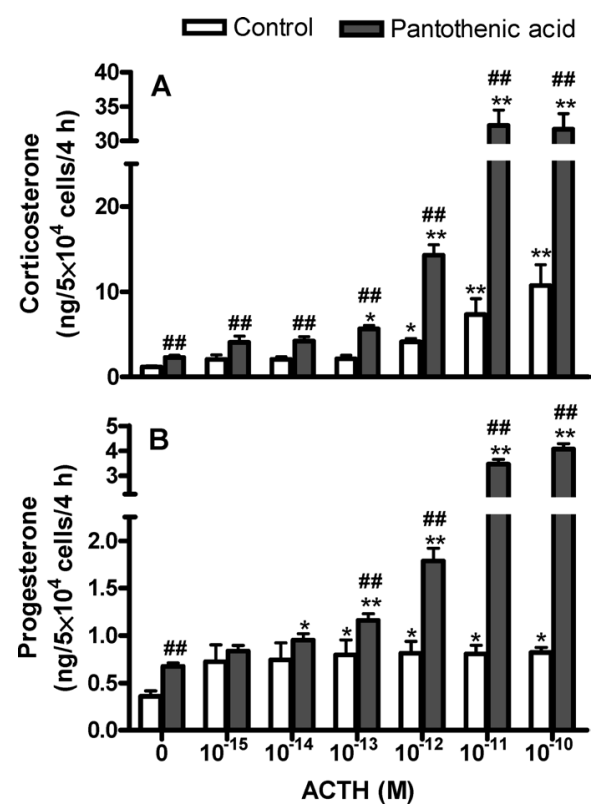

Fig. 1. Effects of ACTH $\left(10^{-15}\right.$ to $\left.10^{-10} \mathrm{M}\right)$ on Release of Corticosterone (A) and Progesterone (B) in Primary Adrenal Cultured Cells from Adult Male Rats Treated with 0 (control) or $0.03 \%$ Pantothenic Acid

Results represent the mean \pm S.E.M. of three different experiments performed in quadruplicate. $*, * * p<0.05, p<0.01$ as compared with basal level $(0 \mathrm{M})$ in each group, respectively. \# $p<0.01$ as compared with control, respectively.

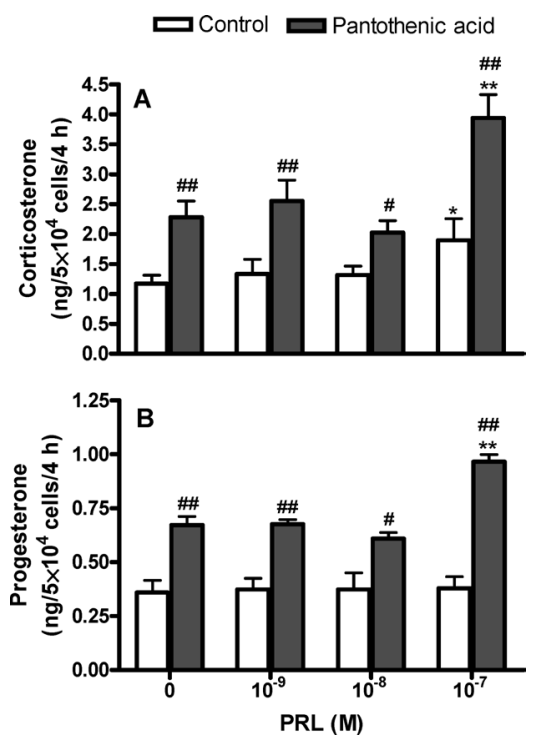

Fig. 2. Effects of PRL $\left(10^{-9}\right.$ to $\left.10^{-7} \mathrm{M}\right)$ on Release of Corticosterone (A) and Progesterone (B) in Primary Adrenal Cultured Cells from Adult Male Rats Treated with 0 (Control) or $0.03 \%$ Pantothenic Acid

Results represent the mean \pm S.E.M. of three different experiments performed in quadruplicate. $*, * * p<0.05, p<0.01$ as compared with basal level $(0 \mathrm{M})$ in each group,

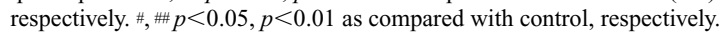

from control rats.

oPRL and ACTH-Stimulated Corticosterone and Progesterone Release in Vitro Co-treatment with oPRL $\left(10^{-7} \mathrm{M}\right)$ produced an increase in the stimulatory effects of ACTH-induced corticosterone and progesterone release in both control and pantothenic acid rats (Figs. 3A, B). The stimulatory effect of oPRL on adrenal sensitivity in response to ACTH was more clear for corticosterone release as compared with progesterone release. oPRL produced an additive

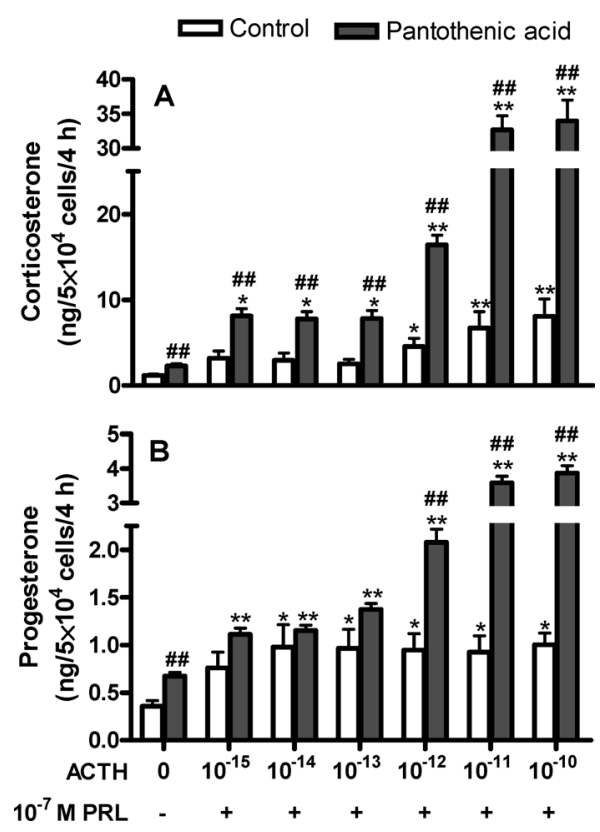

Fig. 3. Effects of $10^{-7} \mathrm{M}$ PRL on ACTH $\left(10^{-15}\right.$ to $\left.10^{-10} \mathrm{M}\right)$ on Release of Corticosterone (A) and Progesterone (B) in Primary Adrenal Cultured Cells from Adult Male Rats Treated with 0 (control) or 0.03\% Pantothenic Acid

Results represent the mean \pm S.E.M. of three different experiments performed in quadruplicate. $*, * * p<0.05, p<0.01$ as compared with basal level $(0 \mathrm{M})$ in each group, respectively. \#p $<0.01$ as compared with control, respectively.

response in ACTH-induced corticosterone release at a low dose in the pantothenic acid group $\left(10^{-15} \mathrm{M}\right)$ as compared with the control group $\left(10^{-12} \mathrm{M}\right)$. The corticosterone and progesterone release in response to co-treatment with oPRL and ACTH were markedly increased in adrenal cells from pantothenic acid rats compared with those from control rats (Figs. 3A, B).

\section{DISCUSSION}

This study demonstrates that pantothenic acid enhanced the basal levels of corticosterone and progesterone in adrenal cells of male rats. These observations imply oversensitivity in the adrenals of the pantothenic acid-treated rats as compared with those of control rats. Moreover, stimulation of dispersed cells isolated from the adrenals of control and pantothenic acid-treated rats demonstrated that the cells originating from the adrenals treated with pantothenic acid required smaller amounts of ACTH $\left(10^{-13} \mathrm{M}\right)$ to increase corticosterone levels significantly above basal compared with those from control adrenals $\left(10^{-12} \mathrm{M}\right)$. This finding supports the hypothesis that the adrenals of the pantothenic acid-treated rats have an increased sensitivity to stimulation with ACTH. Additionally, the results of the present study have demonstrated that the adrenocortical cell culture from pantothenic acidtreated males showed higher sensitivity to ACTH stimulation as expressed in higher corticosterone release.

The mechanism by which pantothenic acid supports the action of ACTH on the adrenal gland has not been fully elucidated. One possibility includes a pantothenic acid-induced promotion of adrenal steroidogenesis. It is well known that adrenal steroidogenesis starts from cholesterol that is a common precursor of all steroid hormones. ${ }^{12,13)}$ It is also well appreciated that cholesterol can be provided either by de novo 
biosynthesis from acetyl coenzyme A or circulating low and high density lipoproteins. ${ }^{14)}$ Since pantothenic acid is a component of $\mathrm{CoA},{ }^{2,15}$ cholesterol synthesis probably operates perfectly in rats treated with panthothenic acid. There is some evidence that cholesterol synthesis is impaired in pantothenic acid deficiency. ${ }^{16)}$ Additionally, a previous study has suggested that cholesterol synthesis from acetate in pantothenic acid deficiency may be operating feebly due to insufficient supplies of CoA. ${ }^{717)}$ Taken together, the present results suggest that pantothenic acid induced adrenal hyperresponsiveness to ACTH stimulation. Additionally, we hypothesize that pantothenic acid stimulation of adrenal steroid release may be due to an increasing of cholesterol synthesis.

In conclusion, these results clearly demonstrate that pantothenic acid supplementation stimulated the secretory ability of corticosterone and progesterone from adrenal cells in male rats. Additionally, these results also indicate that pantothenic acid supplementation induced adrenal hyperresponsiveness to ACTH stimulation, and PRL further stimulated adrenal sensitivity to ACTH.

Acknowledgments We are grateful to Dr. A. F. Parlow and the Rat Pituitary Hormone Distribution Program (NIDDK, NIH, Torrance, CA, U.S.A.) for providing ovine prolactin (AFP10692C) and rat ACTH (AFPRFR7890) for in vitro study, and to Dr. G. D. Niswender, Animal Reproduction and Biotechnology Laboratory, Colorado State University, Fort Collins, CO, U.S.A. for providing antisera to progesterone (GDN337). This study was supported in part by a
Grant-in-Aid for Scientific Research (B-18310044, the Japan Thailand Joint Research) from the Ministry of Education, Culture, Sport, Science and Technology of Japan and the Japan Society for the Promotion of Sciences.

\section{REFERENCES}

1) Plesofsky-Vig N., "Pantothenic Acid," ed. by Shils M., Williams \& Wilkins, Baltimore, 1999, pp. 423-432.

2) Tahiliani A. G., Beinlich C. J., Vitam. Horm., 46, 165-228 (1991).

3) Wolfe A. J., Microbiol. Mol. Biol. Rev., 69, 12-50 (2005).

4) Russell D. W., Cardiovasc. Drugs Ther, 6, 103-110 (1992).

5) Morgan A. F., Vitam. Horm., 9, 164-212 (1951).

6) Ershoff B. H., Slater R. B., Gaines J. G., J. Nutr., 50, 299-316 (1953).

7) Hurley L. S., Morgan A. F., J. Biol. Chem., 195, 583-590 (1952).

8) Hurley L. S., Mackenzie J. B., J. Nutr., 54, 403-415 (1954).

9) Jaroenporn S., Nagaoka K., Ohta R., Watanabe G., Taya K., J. Reprod. Dev., 53, 887-893 (2007).

10) Kanesaka T., Taya K., Sasamoto S., J. Reprod. Dev., 38, 85-89 (1992).

11) Taya K., Watanabe G., Sasamoto S., Jpn. J. Anim. Reprod., 31, 186197 (1985).

12) Arlt W., Stewart P. M., Endocrinol. Metab. Clin. North Am., 34, 293 313 (2005).

13) Harvey P. W., Everett D. J., Springall C. J., J. Appl. Toxicol., 27, 103115 (2007).

14) Azhar S., Leers-Sucheta S., Front Biosci., 8, s998-s1029 (2003).

15) Reibel D. K., Wyse B. W., Berkich D. A., Neely J. R., J. Nutr., 112, 1144-1150 (1982).

16) Morgan A. F., Lewis E. M., J. Biol. Chem., 200, 839-850 (1953).

17) Guehring R. R., Hurley L. S., Morgan A. F., J. Biol. Chem., 197, $485-493$ (1952). 